\title{
Call for Papers: Edited Collection
}

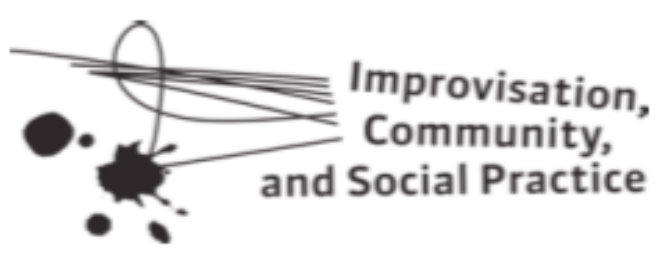

\section{Sound Changes: Improvisation, Social Practice, and Cultural Difference}

As part of Duke University Press's Improvisation, Community, and Social Practice series, this volume proposes an enhanced, interdisciplinary understanding of improvisation as a multivalent, global social practice found within and across different cultural and historical contexts, different national sites and traditions. Books in this new series generally posit musical improvisation as a crucial model for political, cultural, and ethical dialogue and action-for imagining and creating alternative ways of knowing and being known in the world. The books are collaborations among performers, scholars, and activists from a wide range of disciplines. They study the creative risk-taking imbued with the sense of movement and momentum that makes improvisation an exciting, unpredictable, ubiquitous, and necessary endeavor. But are these assumptions necessarily true in the more global contexts in which improvisation is present? Does improvisation necessarily mean the same thing in and across different national sites where the social utility (or not) of improvisation is subject to vastly different contingencies, contexts, and historical circumstances? What kinds of theoretical and case study analysis are required in order to broaden improvisation studies beyond North American and European sites delimited (largely) by specific forms like free jazz, spontaneous composition, and experimental music?

With these questions in mind, a key precept underlying this book is that "improvisation" risks becoming a master trope that erases the multiple differential practices to which it generally refers. We intend for this collection to examine the astonishing diversity of practices that improvisation entails in ways that challenge monological notions of improvisation as a global practice that means the same thing in all circumstances. In that light, the volume explores "sound changes" as the word "changes" oscillates between its function as verb and as noun. The phrase "sound changes" thus references both the differential contexts in which improvisatory sound occurs (and how those change a sound's meaning) and the ways in which sound itself is productive of changes that have an impact on wider spheres of human being.

The editors seek proposals for essays that address a wide range (geographically and culturally) of performance contexts in which improvisation is present as well as a diversity of critical traditions that have been, or should be, brought to bear on improvisatory practices. We are interested in work about music and sound, but also work that examines related improvisational forms such as dance, theater, intermedial performance practices, community organization and activism, transcultural encounters, and so on. As a means of addressing some of the key issues outlined above, we hope to include essays that address one or more of the following questions: How do improvisatory practices build from and challenge social norms and rules in different cultural contexts? How do transcultural exchanges lead to the emergence of hybrid improvisational forms? How do the assumed meanings of improvisational forms change as they travel between and across cultural contexts? How are transcultural, improvisational exchanges enhanced by emergent technologies, and to what extent do emergent technologies define the limits of improvisation as a social practice in certain contexts? How does a cross-cultural understanding of improvisation call into question existing theoretical and political assumptions guiding its study? How does cultural difference determine how improvisation operates in wider spheres of cultural practice? How do "sound changes" signify these differences in ways that mark improvisatory discourses as a site of dissonance rather than consonance?

We are open to work that focuses on other questions as well and authors interested in pursuing other related lines of inquiry and research should contact us directly. To submit a chapter proposal for this edited collection please send an Abstract of no more than 300 words to Daniel Fischlin (dfischli@uoguelph.ca) and Eric Porter (ecporter@ucsc.edu). If selected, chapters should be approximately $6000-10,000$ words in length. The deadline for Abstract submission is October 15, 2013. 